\title{
The role and clinical implications of microRNAs in hepatocellular carcinoma
}

\author{
ZHAO Xue ${ }^{1 \dagger}$, YANG Zhen ${ }^{2 \dagger}$, LI GuangBing $^{1,3}$, LI DongKai $^{1}, \mathrm{ZHAO} \mathrm{Yi}^{4}$, WU Yan ${ }^{5}$, \\ ROBSON Simon C..$^{5}$ HE Lian ${ }^{1}$, XU YiYao ${ }^{1 *}$, MIAO RuoYu ${ }^{1,4^{*}} \&$ ZHAO HaiTao ${ }^{1 *}$ \\ ${ }^{1}$ Department of Liver Surgery, Peking Union Medical College Hospital, Chinese Academy of Medical Sciences and \\ Peking Union Medical College, Beijing 100005, China; \\ ${ }^{2}$ School of Life Science, Fudan University, Shanghai 200433, China; \\ ${ }^{3}$ Department of Liver Transplantation and Hepatobiliary Surgery, Provincial Hospital Affiliated to \\ Shandong University, Jinan 250021, China; \\ ${ }^{4}$ Bioinformatics Research Group, Center for Advanced Computing Technology Research, Institute of \\ Computing Technology, Chinese Academy of Sciences, Beijing 100190, China; \\ ${ }^{5}$ Liver Center and Transplant Institute, Department of Medicine, Beth Israel Deaconess Medical Center, \\ Harvard University, Boston, Massachusetts 02215,USA
}

Received July 5, 2012; accepted September 11, 2012

\begin{abstract}
Hepatocellular carcinoma (HCC) is common and one of the most aggressive of all human cancers. Recent studies have indicated that miRNAs, a class of small noncoding RNAs that regulate gene expression post-transcriptionally, directly contribute to HCC by targeting many critical regulatory genes. Several miRNAs are involved in hepatitis B or hepatitis C virus replication and virus-induced changes, whereas others participate in multiple intracellular signaling pathways that modulate apoptosis, cell cycle checkpoints, and growth-factor-stimulated responses. When disturbed, these pathways appear to result in malignant transformation and ultimately HCC development. Recently, miRNAs circulating in the blood have acted as possible early diagnostic markers for HCC. These miRNA also could serve as indicators with respect to drug efficacy and be prognostic in HCC patients. Such biomarkers would assist stratification of HCC patients and help direct personalized therapy. Here, we summarize recent advances regarding the role of miRNAs in HCC development and progression. Our expectation is that these and ongoing studies will contribute to the understanding of the multiple roles of these small noncoding RNAs in liver tumorigenesis.
\end{abstract}

miRNA, noncoding RNAs, hepatocellular carcinoma, cancer therapy

Citation: Zhao X, Yang Z, Li G B, et al. The role and clinical implications of microRNAs in hepatocellular carcinoma. Sci China Life Sci, 2012, 55: 906-919, doi: 10.1007/s11427-012-4384-x

Hepatocellular carcinoma (HCC) is a primary cancer of the liver; it ranks as the fifth most common malignant cancer and the third leading cause of cancer-related death worldwide. In the United States, HCC accounts for almost all primary liver cancer cases with an incidence of 12.3 and 4.1

$\dagger$ Contributed equally to this work

*Corresponding author (email: xuyiyao@hotmail.com; rabbitmiao@yahoo.cn; zht@ ebiomed.org) cases per 100000 men and women, respectively. Unfortunately, the incidence steadily increased from 1999 to 2008, according to surveillance conducted by the American Cancer Society in 2012 [1]. Chronic hepatitis B virus (HBV) and/or hepatitis $\mathrm{C}$ virus (HCV) infections resulting in hepatic fibrosis and cirrhosis are the major risk factors for HCC, and we are currently seeing the long-term consequence of extensive HCV transmission in the aging baby boomer populations in the United States. In China, HBV 
infection is the major risk factor for HCC [2].

To date, early diagnosis and treatment of HCC are disappointing, as a consequence of the lack of effective and reliable screening methods. Two out of three HCC patients are only diagnosed at the time of advanced carcinoma [3]. In addition, HCC is largely insensitive to most chemotherapeutic agents. New kinase inhibitors are potentially effective, and kinase inhibitors such as sorafenib may help prolong overall survival of patients with HCC and reduce disease recurrence after surgery or ablative therapies [4,5].

Surgical resection and/or liver transplantation remain the best hope for curative treatment of HCC. However, only $5 \%-15 \%$ of HCC patients are currently eligible for surgical intervention, based on evaluation of their liver function and tumor burden [6]. The Milan Criteria and University of California San Francisco Criteria have been used for selection of patients with HCC for liver resection or transplantation. However, the prognosis was poorer in the patients within these criteria. The reason may be the lack of effective methods for early diagnosis $[7,8]$.

Recurrence and metastasis are common in patients who have undergone resection, with a postoperative 5-year survival rate of $30 \%-40 \%$ [9,10]. It is critical to diagnose HCC at an early stage, especially at a molecular level by contrasting expression profiles of crucial genes. Current clinical practice has primarily focused on protein-coding genes and their products as biomarkers such as $\alpha$-fetoprotein (AFP) [11]. However, these biomarkers fail to meet the needs for accurate early diagnosis, prognosis and treatment stratification of HCC because of low sensitivity and specificity. Precise molecular mechanisms for the pathogenesis of HCC are urgently required, hence the requirement to define and then develop other novel molecular tools, for example, miRNAs, as biomarkers.

miRNAs are endogenous small noncoding RNAs consisting of 20-25 nucleotides (nt) that modulate gene expression by promoting mRNA degradation or repressing protein translation through sequence-specific interactions with the 3'-untranslated region (UTR) of target mRNAs. miRNAs are known to play important roles in various physiological processes, for example, development, apoptosis, proliferation, and differentiation [12-19]. Deregulation of miRNA expression has also been implicated in many diseases including cancer. Recent evidence has clearly demonstrated that, other than abnormal epigenetic modifications, dysregulation of miRNA expression may also contribute to aberrant activation of oncogenes, accompanied by inactivation of tumor suppressor genes [20-24].

miRNAs could also interfere with HBV or HCV entry and replication in liver cells, as well as many other fundamental cellular processes such as determining cell cycle checkpoints, apoptosis and cell migration.

In this review, we summarize the molecular mechanisms that underpin the roles of miRNAs in malignant transformation of liver cells, and their potential as biomarkers for
HCC diagnosis and prognosis as well as effective targets for personalized treatment stratification.

\section{Human miRNAs as etiologic factors in HCC and the regulatory network}

\subsection{Roles of miRNAs in virus-induced HCC}

Occurrence of HCC is often associated with chronic infection of HBV or HCV [25]. An HBV-encoded protein, HBx, is thought to play a major role in molecular pathogenesis of HBV-related HCC (HBV-HCC) [26,27] and migration of HCC cells. HBx-transgenic mice or $\mathrm{HBx}$-transfected cells have been used as models for HBV-HCC [28-31], in which several miRNAs have been identified to be involved. miR-143 is one of the most important miRNAs for HBV-HCC development.

Zhao et al. [32] have measured miR-143 expression levels in $\mathrm{p} 21-\mathrm{HBx}$ transgenic mice at different ages during disease progression. The livers of 10-month-old mice lacking neoplastic changes exhibited significantly reduced miR-143 levels. In contrast, at age 22 months, a two-fold increase in miR-143 expression was noted in liver tumors without lung metastasis, and a six-fold increase in those with lung metastasis. In humans, miR-143 was upregulated four-fold in $\mathrm{HBV}-\mathrm{HCC}$ samples without lung metastasis, and eight-fold in HBV-HCC with lung metastasis [33]. However, minimal upregulation of miR-143 was observed in HBV-negative HCC, with or without metastasis.

miR-143 overexpression in HBx-transfected cells significantly promotes cell migration with no substantial effect on cell proliferation or apoptosis [34]. Invasive capacity of these cells is robustly inhibited by cotransfection of antisense oligonucleotides with miR-143. Furthermore, induction of miR-143 by intratumoral administration of p-miR-143 led to seven intrahepatic and two lung metastases in $15 \mathrm{p} 21-\mathrm{HBx}$ transgenic mice [32]. In contrast, no metastasis was found in mice that received control miRNA vector. In vivo repression of miR-143 levels by injection of anti-miR-143 into these mice significantly blocked HCC development and metastases [35]. These data indicate that miR-143 eases HBx-controlled cell migration/invasion both in vitro and in vivo.

miR-29a is also important in promoting HBV-HCC progression, and is dramatically upregulated in p21- $\mathrm{HBx}$ transgenic mice and in HepG2-X and H7402-X cell lines [36]. Overexpression of miR-29a enhances migration of HepG2 cells [37]. Moreover, specific miR-29a inhibitors partially abolish HepG2-X cell migration without affecting HBx expression [38]. Phosphatase and tensin homolog (PTEN), a crucial tumor suppressor, has been identified as one of the target genes of miR-29a. Overexpression of miR-29a in hepatoma cells results in downregulation of PTEN and increases serine phosphorylation of its downstream compo- 
nent, protein kinase B (Akt). PTEN and Akt are known to regulate many fundamental cellular functions including cell proliferation/growth, survival, migration, apoptosis, and metabolism [39,40]. Expression of PTEN leads to dephosphorylation of Akt and inhibition of cell growth and migration [41,42]. Overexpression of PTEN by transient transfection with pcDNA3-PTEN plasmid, or knockdown of Akt by siRNA can abolish the enhanced migration of HepG 2 cells mediated by miR-29a. Thus, miR-29a can ease HBx-induced hepatoma cell migration by modulating PTEN and Akt. In addition, transfection with miR-29a increases mRNA levels of matrix metalloproteinase (MMP)-2 in HCC cell lines, which might also account for miR-29a-mediated cell migration [43]. However, miR-29a upregulation is not always observed in HCC patients. In 11 clinical HCC samples, only four showed upregulation of miR-29a.

$\mathrm{HCV}$ infection is another independent risk factor for HCC. Infection with $\mathrm{HCV}$ results in increased oxidative stress in infected hepatocytes, causing further hepatocellular damage that could ultimately lead to malignant hepatocyte transformation $[44,45]$. miR-196 has been found to inhibit $\mathrm{HCV}$ expression and repress $\mathrm{HCV}$-induced oxidative damage. Transfection with miR-196 mimics significantly reduces HCV replication [46]. Two 6-nt sites within the HCV Con1 genome have been predicted to be complementary to a miR-196 region, implying that miR-196 inhibits HCV expression by directly targeting its Con 1 genome. Additionally, miR-196 has been demonstrated to block HCV replication through its action on NS5A gene in the JFH1 region of the HCV genome [31]. Similar downregulation of HCV NS3 protein expression by miR-196 has also been confirmed in an HCV J6/JFH1 cell culture system [47]. Moreover, miR-196 is able to repress oxidative damage by targeting the transcription regulator protein Bach1 [48]. Bach1 is a well-established repressor of the heme oxygenase 1 (HMOX1) gene [49,50], a major cytoprotective enzyme with antioxidant and anti-inflammatory activities [51-53]. miR-196 induction downregulates Bach1 and upregulates HMOX1 in human hepatoma 9-13 cells [54]. Therefore, miR-196 plays a protective role in HCV-HCC by directly targeting $\mathrm{HCV}$ genomes or indirectly regulating Bach1 and HMOX1 expression/function.

miR-122 is liver-specific and the most abundant miRNA in the liver [55,56]. It is required for efficient replication of $\mathrm{HCV}$ in vitro and in vivo. Expression of miR-122 in HepG2 cells leads to efficient HCV RNA replication and infectious virion production [37]. When a missing $\mathrm{HCV}$ receptor was coexpressed with miR-122, HepG2 cells could efficiently facilitate viral entry and the entire life cycle of HCV. There are two predicted miR-122 binding sites in the $3^{\prime}$ and $5^{\prime}$ noncoding regions of the $\mathrm{HCV}$ genome. The putative $5^{\prime}$ noncoding region is required for replication of HCV RNA $[57,58]$ and possibly contributes to liver tropism of HCV by accelerating binding of ribosomes to viral RNA to stimulate HCV translation [59]. miR-122 antagomir can inhibit repli- cation of HCV, abundance of HCV core RNA, and expression of HCV nonstructural proteins (NS3 in CNS3 cells and NS3-5B in 9-13 replicon cells), in a time- and dosedependent manner [51,60-63]. These findings are suggestive of miR-122 as a potential target for antiviral interventions in HCV patients [37,57,64-67].

In addition, miR-141 has also been shown to enhance $\mathrm{HCV}$ replication and its antagomir reduces replication of $\mathrm{HCV}$ [68]. An increase in miR-141 is often associated with decreased expression of DLC-1 (deleted in liver cancer 1), a tumor suppressor gene frequently deleted in HCC and other solid human tumors [67]. HCV-infected hepatocytes show enhanced proliferation that could be mitigated by overexpression of DLC-1, indicating that miR-141 might also promote $\mathrm{HCV}$-induced tumorigenesis [69].

To evaluate global and dynamic expression of host miRNAs as well as alterations in mRNA levels during acute $\mathrm{HCV}$ infection, we have performed a comprehensive microarray analysis [70]. One hundred and forty-two miRNAs were identified as differentially expressed in JFH-1 $\mathrm{HCV}$-infected and UV-inactivated HCV-infected Huh7.5.1 cells. Increased levels of miR-181a, miR-210 and miR-221 were observed in JFH1-infected Huh7.5.1 cells; and miR-455-3p slightly suppressed HCV propagation in vitro; as compared to UV-inactivated control cells [71]. Virus entry assays demonstrated that overexpression of miR-923 or inhibition of miR-149*, miR-373*, miR-638, miR-888, miR-940, miR-1181 or miR-1234 enabled entry of HCV pseudoparticles. When using the genotype $1 \mathrm{~b}$ replication system, gains in miR-221 and miR-455-3p and losses in miR-887 and miR-940 expression were noted. An increase in $\operatorname{miR}-24$ expression and a reduction in miR-149* and miR-373* expression suppressed HCV RNA abundance.

\section{2 miRNAs add complexity to epigenetic modification}

Aberrant patterns of epigenetic modifications, such as DNA methylation or histone acetylation, are important molecular mechanisms underpinning development of cancer, including HCC [72-75]. Recent evidence has suggested links between miRNAs and epigenetic pathways in hepatocarcinogenesis.

Viral genes can be a major regulator in DNA methylation [76]. miR-152 is frequently downregulated in HBV-HCC mice and the HepG2.2.15 cell line. miR-152 expression is inversely correlated with DNA methyltransferase (DNMT)1 expression in HBV-HCC as well as in HepG2, HepG2.2.15 and LO2 cell lines. Upregulation of DNMT1 as a result of miR-152 downregulation has been observed during HCC development. miR-152 may participate in $\mathrm{HBV}$-induced epigenetic modifications through DNMT1. Inhibition of miR-152 results in global DNA hypermethylation as well as increased methylation of two tumor suppressor genes, glutathione S-transferase $\pi 1$ (GSTP1) and E-cadherin 1 (CDH1) [77]. Both genes have previously been shown to be silenced after DNA methylation in HBV-HCC. Therefore, indirect 
inactivation of GSTP1 and CDH1 by miR-152 may also contribute to pathogenesis of this malignancy [78].

Besides targeting DNA-methylating enzymes such as DNMT1, miRNA expression could also be reciprocally affected by DNA methylation and histone acetylation [79]. When the status of DNA methylation and histone acetylation were manipulated in HepG2, Hep3B, SKHep1, SNU-449, Huh7 and PLC/PRF5 cells, 23 miRNAs were dysregulated, among which, changes in miR-1-1 levels were the most robust. Expression of miR-1-1 was markedly reduced in HCCs, but not evident in the matched fibrotic foci of cirrhotic livers. CpG islands located upstream of miR-1-1 were methylated in HepG2 and Huh7 cells, whereas hypomethylation of its $\mathrm{CpG}$ islands upregulated miR-1-1 expression. Indeed, miR-1-1 methylation at $\mathrm{CpG}$ island-81 in HCCs was found to be a tumor-specific event. Ectopic expression of miR-1-1 in HepG2 cells caused a reduction in cell proliferation, growth and clonogenic survival by inducing apoptosis and inhibiting cell cycle progression, and mitigated the cancer-cell characteristics of these cells. Therapeutic intervention with hypomethylating agents could inhibit HCC cell growth by increasing miR-1-1 expression to inhibit expression of its two downstream oncogenes, MET (MNNG HOS transforming gene) and FoxP1 (Forkhead box protein P1) [80]. These data imply that compounds interfering with epigenetic modifications, such as DNMT and histone deacetylase inhibitors, may serve as potential novel antitumor drugs for HCC patients $[81,82]$.

\subsection{Regulation of intracellular signaling networks by miRNAs in HCC}

miRNAs play an essential role in regulating the complex signaling networks during tumorigenesis of HCC. A number of deregulated miRNAs are involved in mitochondrion-mediated apoptosis (Figure 1). An imbalance between pro- and antiapoptotic members of the Bcl-2 (B-cell lymphoma 2) family that are modulated by several miRNAs, results in permeability changes of mitochondrial membrane. Two proapoptotic members, Bmf and Bim, are targeted by miR-221 and miR-15, respectively. Three antiapoptotic members, Bcl-2, Mcl-1 and Bcl-w are targets of miR-29, miR-101 and miR-122, respectively [83]. Bcl-2 has also been identified as a target of miR-16 [78]. miR-16 is one of the epigallocatechin gallate (EGCG) upregulated miRNAs. EGCG treatment induces apoptosis with downregulation of Bcl-2 in HepG2 cells. In contrast, blocking miR-16 using a specific antagomir attenuates EGCG-induced Bcl-2 downregulation and apoptosis in these cells $[84,85]$. Bcl-w is also targeted by miR-15b. miR-15b inhibition increases HCC cell proliferation and blocks TRAIL (TNF-related apoptosis-inducing ligand) induced apoptosis, whereas ectopic expression of miR-15b precursor decreases proliferation and enhances apoptosis [86].

Let-7c and let-7g miRNAs have been shown to regulate Bcl-xl. Let-7 is downregulated in Huh-7 cells, and associated with upregulation of $\mathrm{Bcl}-\mathrm{xl}$. In contrast, overexpression of let-7c or let-7g decreases Bcl-xL levels in Huh7 and

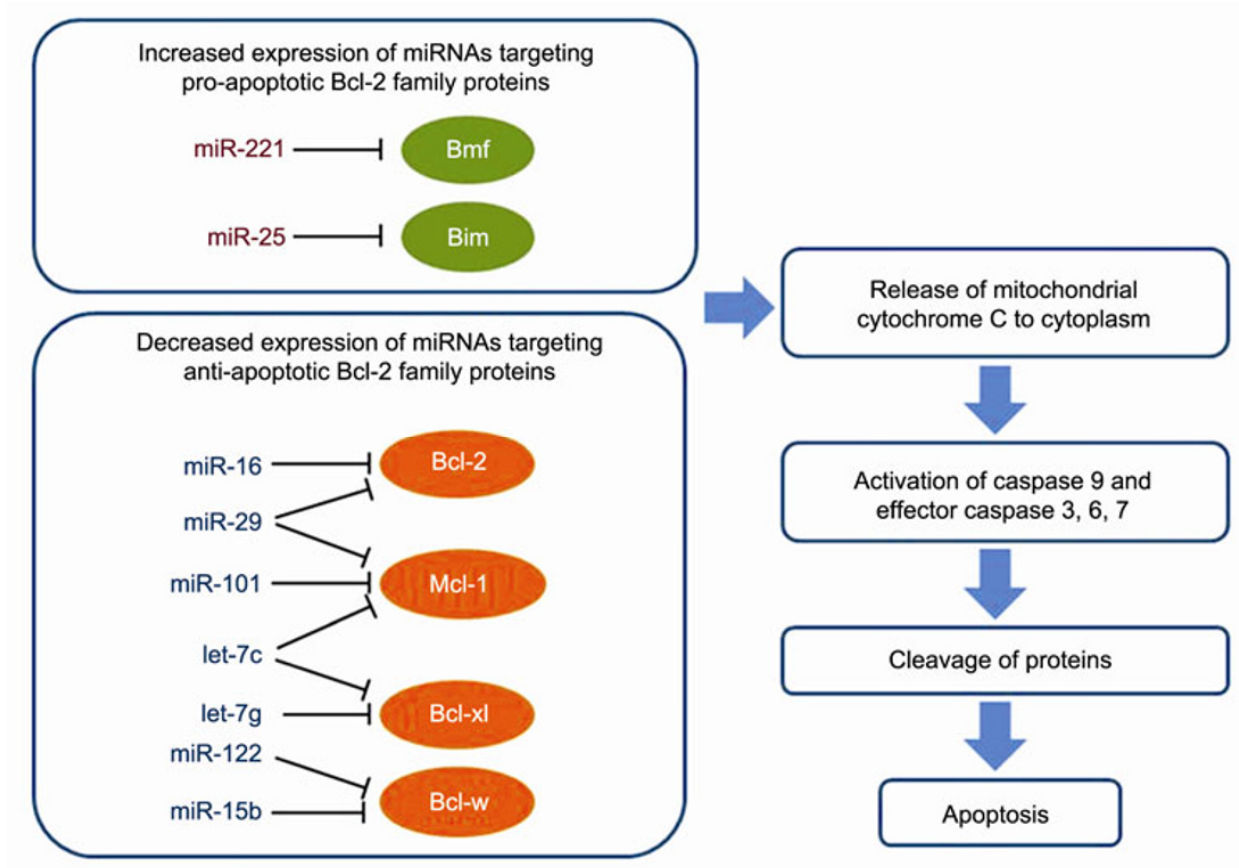

Figure 1 Members of the Bcl-2 family targeted by miRNAs. An imbalance between the pro- and antiapoptotic members of the Bcl-2 family results in permeability changes in the mitochondrial membrane. This leads to release of cytochrome c into cytoplasm from mitochondria, thereby inducing apoptosis. 
HepG2 cells, and reporter assays have revealed direct regulation of Bcl-xl mRNA by let-7c or let-7g. HCC with low levels of let-7c shows higher Bcl-xL protein expression than that expressing abundant let-7. These data are indicative of a negative modulation of $\mathrm{Bcl}-\mathrm{xL}$ expression at mRNA and protein levels by let-7 miRNA [87]. Downregulation of these miRNAs in HCC cells enables them to evade apoptosis and survive in nutrient-depleted and hypoxic microenvironments.

In addition, the G1/S checkpoint in the cell cycle is tightly controlled by multiple mechanisms, such as E2F/Rb (elongation factor 2/retinoblastoma protein), cyclin D/CDK4/CDK6 (cyclin-dependent kinase4/6), cyclin E/CDK2, and p27/57 complexes. Several miRNAs have been shown to control G1/S checkpoint by regulating these molecular complexes (Figure 2). For example, miR-26a, miR-221 and miR-195 modulate cyclin D/CDK4/CDK6 and cyclin E/CDK2 complexes [83]; and miR-222, a homolog of miR-221, controls CDKN1B/p27/Kip1 (kinase inhibitor protein) [88]. A consistent decrease in p27 protein has been observed in HCC patient samples overexpressing miR-221/222. Ectopic expression of miR-221 and miR-222 in HeLa and 293T cells reduces p27 protein levels [89].

miR-34a also regulates G1/S transition molecules including cyclin D1, CDK4 and CDK2 in HCC. Induction of miR-34a in HepG2 cells leads to accumulation of cells in G1 phase, thereby suppressing cell proliferation, migration and invasion [87]. As a downstream target of tumor suppressor protein 53 (p53), miR-34a also functions as an intermediate between p53 signaling and the cell cycle pathway [90]. miR-193b blocks cell proliferation by inducing G1 arrest via cyclin D1 in SK-Hep-1 cells. It dramatically suppresses the ability of these cells to form colonies in vitro and to develop tumors in nude mice [91]. CDK6 is a target of miR-124 and miR-203. In several cell lines, ectopic expression of miR-124 decreases the number of cells in $\mathrm{S}$ and G2/M phases, and increases cells in G0/G1 phase. Expression of miR-203 reduces the number of cells at G0/G1, S and $\mathrm{G} 2 / \mathrm{M}$ phases, and increases cells at sub-G1 phase. These data suggest that cell growth suppression by miR-124 is predominantly mediated through the induction of cell cycle arrest at the G1/S checkpoint, whereas suppression by miR-203 is via induction of apoptosis [92]. Downregulation of these miRNAs therefore allows the cells to surpass the checkpoints in the cell cycle and undergo uncontrolled proliferation.

Receptor tyrosine kinases (RTKs) are cell surface receptors that transmit extracellular stimuli to intracellular signaling responses. RTK transduction activates a series of proteins to elicit downstream signaling cascades that eventually alter transcription of a myriad of genes controlling critical cellular functions, such as proliferation, apoptosis and survival. Several miRNAs have been shown to participate in RTK signaling (Figure 3). PTEN is a negative regulator of the phosphoinositide 3-kinase (PI3K)/Akt signaling pathway $[43,83]$, and is a target for miR-21, miR-222 and miR-29a. c-Myc is a target of miR-223 and let-7c. An inverse correlation between miR-223 and c-Myc has been noted in HepG2 cells and HCC samples. Levels of miR-223 are reduced in $\mathrm{HCC}$ and adjacent tissues in comparison with HCC-free liver tissues, as well as in HepG2 cells, in contrast to L02 fetal liver cells. Thus, miR-223 may contribute to hepatotumorigenesis by negatively regulating c-Myc expression $[93,94]$.

miR-199a-3p has been shown to target c-met (the only receptor for hepatocyte growth factor (HGF)) in a luciferase reporter assay. Restoring attenuated levels of miR-199a-3p in HepG2 cells leads to G1 arrest, reduces invasive capability, enhances susceptibility to hypoxia, and increases sensitivity to doxorubicin-induced apoptosis [90]. miR-199a-3p may also participate in c-met signaling by indirectly modulating CD44, which is responsible for two consecutive steps in the HGF/c-Met signaling cascade [94-96]. Collectively, these miRNAs have critical roles in RTK signaling that affect cell growth, proliferation, migration and invasion.

\subsection{Clinical implications of miRNAs in HCC}

It has been suggested that miRNAs have clinical relevance as pathological markers for early diagnosis, classification, and prognostic stratification of HCC patients. Furthermore, miRNAs per se or anti-miRNA oligonucleotides could be used to modulate hepatocellular functions, indicating the therapeutic potential of miRNAs as targeted molecular therapy for the treatment of HCC patients.

\subsection{1 miRNAs as biomarkers for diagnosis of HCC}

Differential expression patterns of miRNAs have been observed between normal liver and liver cancer tissues, preneoplastic and neoplastic lesions, as well as liver cancer and other types of solid tumors. Such differences exist not only intratumorally, but also in the blood of HCC patients. Serum miRNAs are particularly resistant to RNase digestion, suggesting that circulating miRNAs are sufficiently stable to serve as clinical biomarkers [97]. The fluctuations in blood miRNAs have been directly linked to lesion severity [97-99]. These findings provide evidence supporting bloodbased measurement of tumor-derived miRNAs as a new potential approach for detection of solid human cancers [100].

Using a rat model of chemically induced hepatotumorigenesis, aberrant fluxes of circulating miRNAs were observed in the serum with neoplastic lesions such as hepatocellular adenoma and HCC, and in those with preneoplastic lesions, for example, foci of hepatocellular alteration. Several circulating miRNAs (inclusive of let-7a, let-7f, miR-34a, miR-98, miR-331, miR-338, and miR-652) were gradually elevated during progression of hepatotumorigenesis. Serum levels of let-7a, let-7f and miR-98 were significantly increased even at very early stages of hepatocarcinogenesis. Thus, these miRNAs could be used to monitor the 


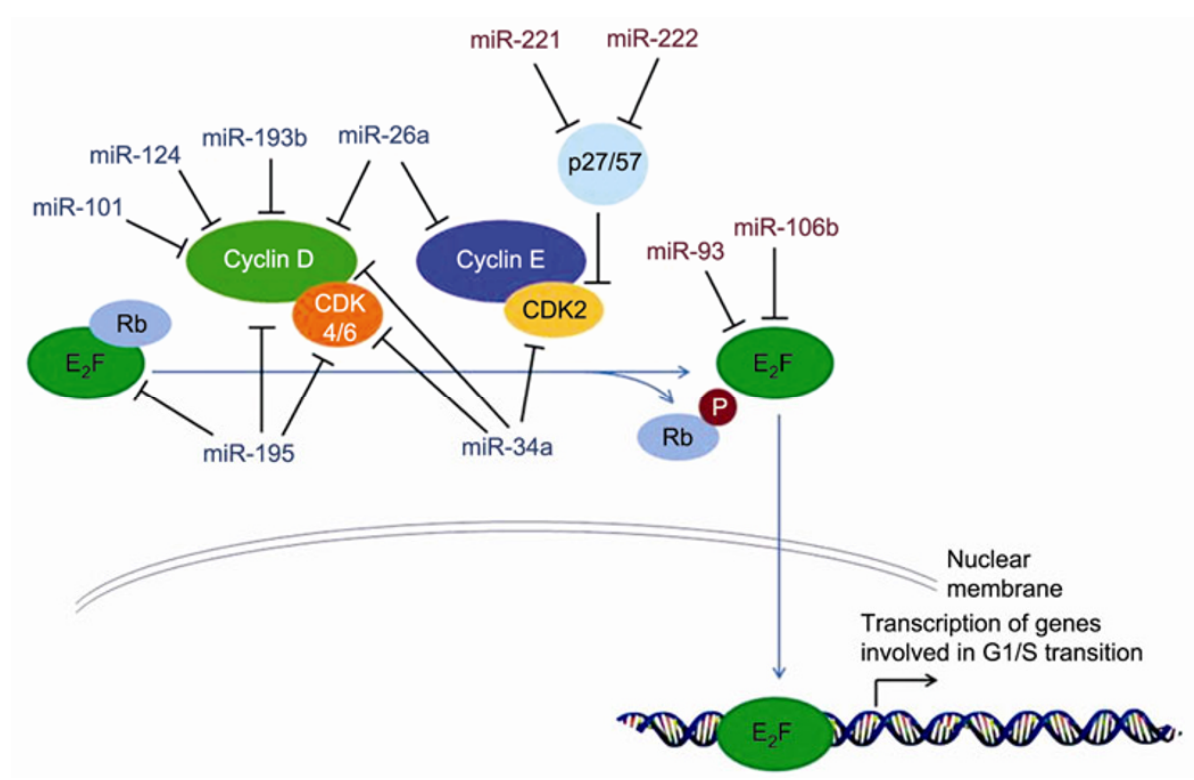

Figure 2 Cell cycle checkpoints controlled by miRNAs in HCC. The key molecules controlling G1/S checkpoints (E2F/Rb complex, cyclin D/CDK4/6 complex, cyclin E/CDK2 complex and p27/57) have been shown to be directly regulated by multiple miRNAs.

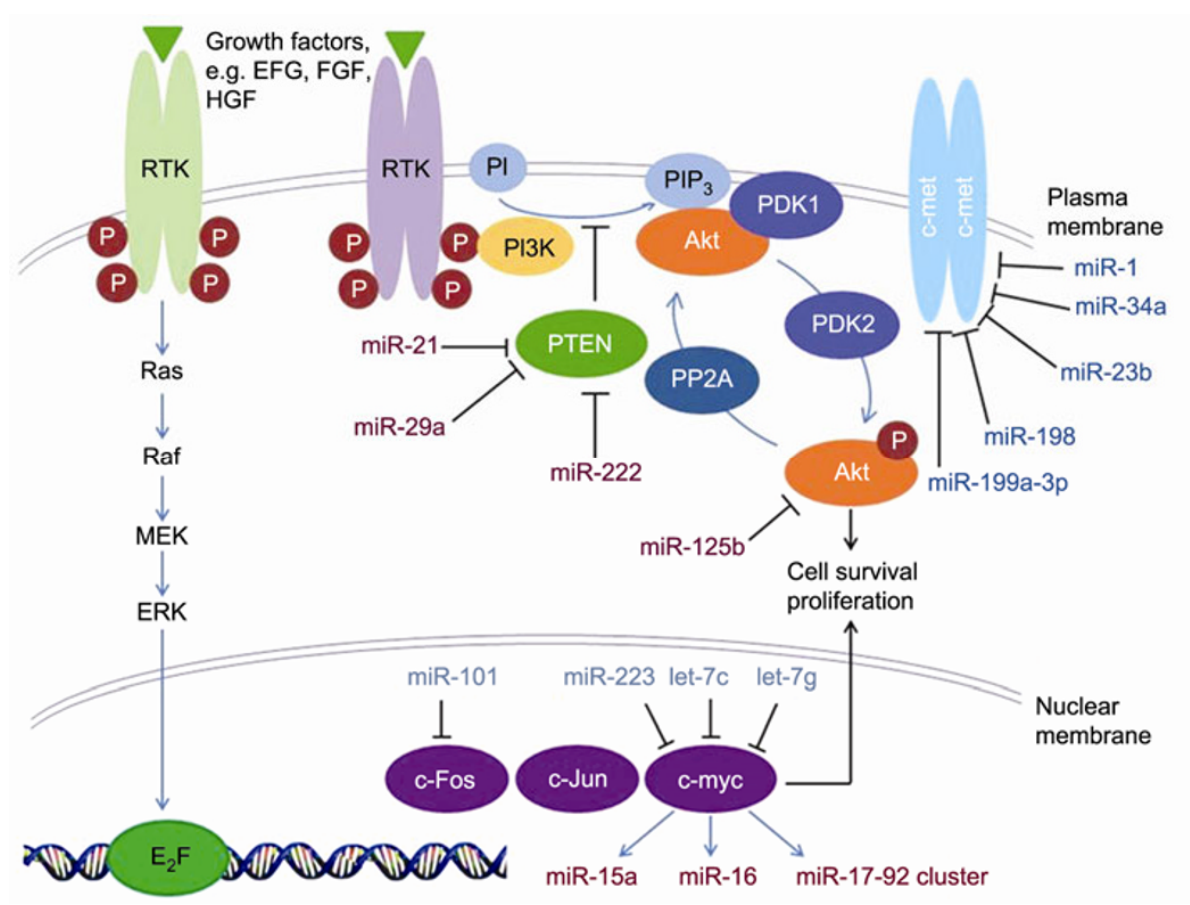

Figure 3 Roles of miRNAs in RTK-mediated pathways in HCC. This includes Ras-Raf-MEK-ERK cascade and PI3K-Akt pathway. EGF, epidermal growth factor; FGF, fibroblast growth factor; HGF, hepatocyte growth factor.

progression of HCC development [101].

Plasma miRNA expression profiles have been analyzed in healthy volunteers and patients with chronic HBV, cirrhosis, or HBV-HCC [102]. A miRNA panel (including miR-122, miR-192, miR-21, miR-223, miR-26a, miR-27a, and miR-801) has been proven to provide a high diagnostic accuracy of HCC, regardless of cancer stage (Barcelona Clinic Liver Cancer stages 0, A, B, and C). This miRNA panel can also distinguish HCC patients from those with chronic hepatitis $\mathrm{B}$, cirrhosis, or healthy controls, offering a valuable tool to diagnose early-stage HCC [103]. By contrasting plasma miRNA profiles in patients with HCC and liver cirrhosis, significant upregulation of 26 and 22 miRNAs was observed, respectively [104]. Unsupervised hierarchical clustering analysis further demonstrated that plasma pools from different patient groups had distinct miRNA 
spectra.

In another independent cohort, serum levels of miR-885-5p were significantly higher in patients with HCC, liver cirrhosis and chronic hepatitis B than in healthy controls or controls with other types of cancer, for example, gastric cancer. miR-885-5p is sensitive and specific in discriminating patients liver pathology from healthy individuals. No correlation between miR-885-5p and liver function parameters (including AFP, alanine aminotransferase, aspartate aminotransferase and $\gamma$-glutamyl transpeptidase) has been observed in patients with liver pathology [104].

In a similar approach, after profiling patients with $\mathrm{HBV}$, $\mathrm{HCV}$ and HBV-HCC and control groups, 13 miRNAs were found to be differentially expressed in HBV serum and six were significantly upregulated in HBV-HCC samples. In addition, a combined panel of miR-23b, miR-423, miR-375, miR-23a and miR-342-3p or of miR-25, miR-375 and let-7f could distinguish HBV-HCC from controls. A combination of miR-10a and miR-125b could differentiate HBV-HCC from HBV infection [105]. A panel of miR-16, miR-195 and miR-199a alone or together with conventional serum markers, can help to separate HCC from chronic liver diseases [106]. miR-21, miR-221, miR-222 and miR-224 were overexpressed in sera from HCC patients when compared with healthy controls, and high level of miR-221 positively correlated with tumor size, cirrhosis and tumor stage [107]. However, elevated serum levels of miR-21, miR-122 and miR-223 were also detected in patients with chronic hepatitis. Indeed, serum miR-21 and miR-122 in these patients were even higher than in patients with HCC. Therefore, these miRNAs have strong potential to serve as novel biomarkers for liver injury but not specifically for HCC [108]. Taken together, serum miRNA profiles can be used as novel complementary and noninvasive biomarkers for HBV infection and early detection and assessment of liver pathology. This would greatly benefit patients with liver disease who otherwise would have missed the curative treatment window from early effective interventions and optimal therapy.

\subsection{2 miRNAs as biomarkers for differential diagnosis of $\mathrm{HCC}$}

Distinguishing HCC from metastatic tumors of the liver is important for prognostic and therapeutic practices in clinic. This differential diagnosis can be difficult because metastatic tumors of the liver, especially adenocarcinomas, may mimic the morphology and immunoregulation of HCC. Although current clinical diagnostic procedures, such as modern pathological and advanced imaging technology, have improved the diagnosis of liver cancer, the primary site of the cancer remains unknown in many patients, even after autopsy [109]. Therefore, molecular biomarkers that are specifically indicative of either HCC or metastatic adenocarcinomas are useful and urgently needed.

miRNAs have been profiled in tumor samples including primary HCC, primary tumors of epithelial origin, meta- static tumors in the liver of epithelial origin, and adenocarcinoma metastases to the liver of unknown origin, to identify tumor-specific biomarkers [110]. Although expression of miR-122 is liver specific [111], high miR-122 levels have also been found in liver metastasis samples because of inevitable contamination from adjacent liver tissues, excluding the use of miR-122 as a good diagnostic marker. Members of the miR-200 family including miR-200a, miR-200b, miR-200c, miR-141, and miR-429 are strongly expressed in primary tumors of epithelial origin in the gastrointestinal (GI) tract, but are not found in HCC. In contrast, miR-126 is overexpressed in HCC as compared to non-HCC metastatic tumors. The combination of miR-200c and miR-141 or miR-126 can distinguish between non-HCC and HCC samples. miR-205 and miR-194 can identify primary tumors of GI and non-GI epithelial origin. These data provide strong evidence suggesting the possibility to differentiate the origins of liver metastasis [110]. Other than pathological examinations, expression profiles of these miRNAs offer an alternative approach that is more sensitive, reliable and accurate to identify primary HCC from metastatic adenocarcinomas in the liver.

\subsection{3 miRNAs as predictors of HCC prognosis}

For postoperative HCC patients, metastasis and recurrence are the major obstacles for long-term survival. Molecular biomarkers correlated with these processes could be useful clinically in disease prognosis. miRNA-based molecular signatures that could differentiate between tumorous and nontumorous tissues have been used in HCC prognosis. miR-139-5p expression is markedly decreased during HCC progression from nontumorous livers with chronic hepatitis or cirrhosis to early-stage HCC (pathological TNM stage I/II), and then to late-stage HCC (pathological TNM stage III/IV). Clinicopathological analysis has revealed that miR-139-5p downregulation in HCC is accompanied by other aggressive pathological features: advanced tumor stages; presence of venous invasion and tumor microsatellite formation; absence of tumor encapsulation; poor tumor cellular differentiation (Edmondson grade III/IV); and distant extrahepatic HCC metastasis; in association with poor 2-year disease-free survival and 5-year overall survival [112]. In addition, levels of miR-96 gradually increase during progression from healthy liver to nontumorous liver tissues, reaching the highest levels in overtly tumorous tissues [113]. Expression of miR-96 in nontumorous tissues and tumor/non-tumor ratio of miR-96 is positively and negatively correlated with HCC recurrence, respectively [113]. Upregulation of miR-222 in HCC tissues is also positively correlated with advanced stages of HCC and shorter disease-free and overall survival [114].

Moreover, together with the miRNA signatures discovered in tumorous and nontumorous tissues, a 20-miRNA signature has also been identified that distinguishes HCC patients with intrahepatic metastases from those without 
metastases. It has further been demonstrated that HCC patients with low let-7g levels have poor outcomes compared with those with high levels of let-7g [115]. Another 20-miRNA signature can differentiate between HCC patients with hematogenous metastases and those without metastases. This signature is associated with the survival of $\mathrm{HCC}$ patients and patients with early stage $\mathrm{HCC}$, and could be used to predict recurrence. Further analysis has revealed that this 20-miRNA predictor is significantly and positively correlated with tumor size, tumor encapsulation, microvascular invasion, and TNM stage [116], inferring its potential as a survival predictor to evaluate the risks of metastasis and recurrence.

\subsection{4 miRNAs in treatment stratification of HCC}

Surgery is currently the major curative treatment option for HCC. Oral medications to treat HCC are limited. Sorafenib, a multi-kinase inhibitor effective in enhancing overall survival of patients with advanced HCC [117], is the only oral drug recently approved by the US Food and Drug Administration. Sorafenib has antiproliferative activity in liver cancer cell lines. It can also limit tumor angiogenesis and tumor cell signaling as well as increase tumor-cell apoptosis in a mouse xenograft model of human HCC [118]. miRNAs have been shown to be involved in sorafenib-mediated antitumor processes. miRNA profiling data have indicated that, after treatment with a low dose of sorafenib, levels of miR-30a-3p, miR-194*, miR-219-1-3p, miR-522, miR-548c-5p, miR-629, miR-664, miR-1260, miR-1274a, miR-1274b, miR-1290, and miR-1291 are dramatically increased, whereas miR222* and miR-548b-5p are reduced in HepG2 cells. miR-1274a, the most abundant among these 14 miRNAs, downregulates ADAM9 (disintegrin and metalloproteinase domain-containing protein 9), a positive regulator of cell growth, migration and angiogenesis [119-122,123].

Clonogenic capacity of miR-122-expressing HepG2 cells is substantially reduced by sorafenib and associated with increased apoptosis, in a dose-dependent manner. Similarly, in miR-122-expressing SK-Hep1 cells, sorafenib induces a reduction of antiapoptotic protein $\mathrm{Mcl}-1$ and an increase in apoptosis. Minimal sorafenib effects have been noted in cells that do not express miR-122. Ectopic expression of miR-122 returns the hypoactive apoptotic pathway back to normal levels by arresting SK-Hep1 cells at G1 phase. Thus, miR-122 is considered to promote the growth inhibitory property of sorafenib, as well as to sensitize HCC cells to apoptotic stimuli [124].

In addition, sorafenib greatly reduces the viability of Huh7 cells, and this is markedly enhanced by transfection with let-7c miRNA, implying that let-7 miRNA elicits sorafenib-induced apoptosis and cytotoxicity in hepatoma cells. However, sorafenib does not affect expression of $\mathrm{Bcl}-\mathrm{xL}$, another antiapoptotic protein family member that is a target of let-7, suggesting that sorafenib and let-7 synergistically induce apoptosis via distinct pathways. It is likely that let-7/Bcl-xL signaling may potentiate tumoricidal activity of sorafenib [87].

Interferon (IFN)- $\alpha$ has also been used to treat HCC. Many miRNAs have been linked to patient survival following IFN- $\alpha$ treatment. Patients with low levels of intratumor miR-26a have a dramatic improvement in overall survival after receiving IFN- $\alpha$. Patients with high miR-26a levels are not responsive to IFN- $\alpha$. Similar results have been obtained with miR-26b. Statistical analysis has revealed a positive correlation between miR-26 expression and efficacy of IFN- $\alpha$ on patient survival. miR-26 appears to be an independent predictor for patient response to IFN- $\alpha$ treatment [125]. Taken together, these miRNAs may help to evaluate and stratify HCC patients for an optimal personalized therapy.

\section{Conclusion and perspectives}

Over the past decade, the numbers of identified human miRNAs have increased dramatically. Studies have revealed that the differential expression of these multiple miRNAs is related to progression of various diseases, especially cancer. The first report involving miR-15 and miR-16 in tumors and malignancy was published in 2002. Deregulation of these two miRNAs has been observed in many cases of B-cell chronic lymphocytic leukemia [126]. Another miRNA gene, the miR-17-92 cluster, was later demonstrated to be upregulated in B-cell lymphoma and accelerated c-Myc-induced tumorigenesis [70,127,128]. Subsequently, involvement of miRNAs in HCC has also been identified [129].

Many databases, such as miR2Disease [130], S-MED [131] and dbDEMC [132], have been established to provide information regarding miRNAs and their relationship to various human diseases. Our understanding toward the links between cancer and miRNAs has grown rapidly in recent years. Studies have demonstrated that many miRNA genes are located at cancer-related loci, and thus alterations in these miRNAs may lead to cancer $[133,134]$. Additionally, expression profiles of miRNAs during tumorigenesis can be used as novel biomarkers to distinguish different types of cancer, and is believed to be more informative and accurate than mRNAs $[135,136]$. This provides us a valuable tool for diagnosis and prognosis as well as effective targets for prevention and treatment of human cancers. This current review focuses on roles of miRNAs in all aspects of HCC, and discusses molecular mechanisms underlying how liver cancer occurs and progresses.

To date, 132 miRNAs (out of 1527 identified in the human genome) have been linked to HCC (Table 1). Some of them are of clinical significance, and are valuable in diagnosing or predicting the prognosis of HCC. These miRNAs could be major factors and used for identification and classification of liver cancer. It has been previously shown that downregulation of a panel of miRNAs (including miR-122, 
Table 1 Deregulated miRNAs in $\mathrm{HCC}^{\mathrm{a}}$

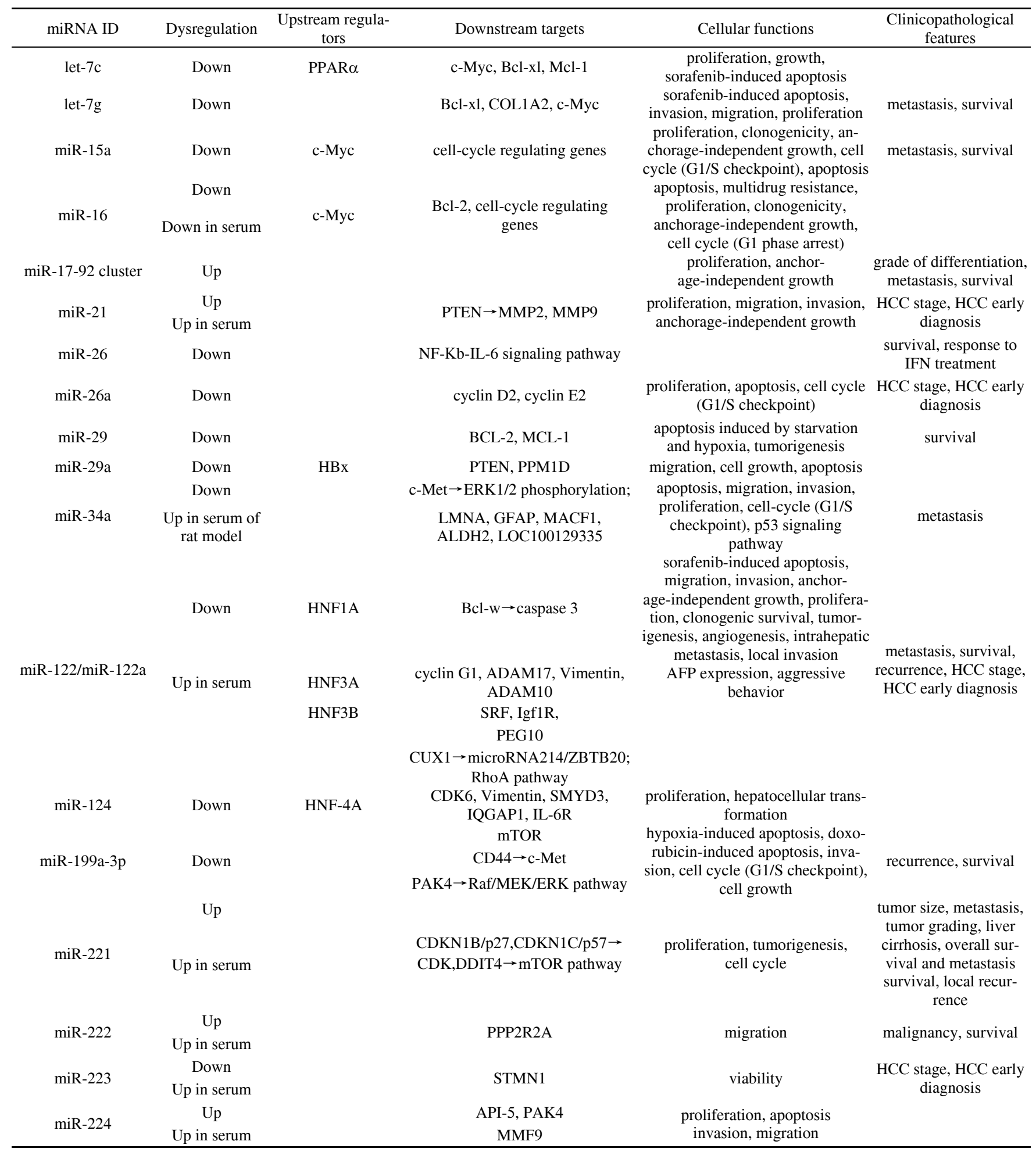

a) PPAR $\alpha$, peroxisome proliferator-activated receptor alpha; PPM1D, protein phosphatase, $\mathrm{Mg}^{2+} / \mathrm{Mn}^{2+}$ dependent, 1D; LMNA, Lamin A/C; GFAP, glial fibrillary acidic protein; ALDH2, aldehyde dehydrogenase 2.

miR-192, miR-21, miR-223, miR-26a, miR-27a, miR-146a, miR-215, miR-224, miR-574-3p, miR-801, and miR-885-5p) in serum can be used for early diagnosis of $\mathrm{HCC}$, and in tissue biopsies to distinguish patients with HCC from those with chronic hepatitis B, cirrhosis, and healthy controls. In addition, expression of miR-16, miR-21, miR-195, miR199a, miR-221, miR-222 and miR-224 in serum can distinguish HCC from healthy controls. Therefore, together with 
pre-existing imaging methods, a panel of miRNAs has great potential in assisting with diagnosis, differential diagnosis, and tumor grading.

However, expression patterns of most miRNAs in HCC constantly change during disease progression, such as from acute hepatitis, chronic fibrotic disorders, and cirrhosis. Xu et al. have reported that serum levels of miR-21, miR-122 and miR-223 are significantly higher in patients with HCC than in healthy volunteers. However, blood levels of miR-21 and miR-122 in patients with chronic hepatitis are higher than those with HCC [108]. These miRNAs could potentially serve as novel biomarkers for liver diseases but cannot be used exclusively for HCC. Most of the published data have used healthy liver tissues as controls. Whether comorbidity interferes with the sensitivity and specificity of miRNA expression in diagnosing HCC remains unclear.

We have investigated the potential relationship between HCC-related miRNAs and other diseases. Some miRNAs are involved in a number of diseases besides HCC. miR-122, for example, is associated with breast, gastric and kidney cancers and malignant melanomas, as well as HCC. miRNAs derived from tumors of other origins may also contribute to abnormal levels in blood, and cannot be used as a solitary indicator for liver disease. Hence, comorbidity should be considered when integrating miRNA profiles into HCC diagnosis.

It has been shown that dysregulation of many target genes involved in fundamental cellular functions by aberrant expression of miRNAs could be the major cause of liver cancer progression, indicative of their potential as therapeutic targets for cancer treatment. Modifications in miRNA expression, using miR-mimics or antagomirs in hepatoma cell lines or nude mouse models, can alter growth, metastasis and size of HCC. However, the potential side effects should be carefully considered and examined before translating these treatment strategies into the clinic. miRNAs are involved in a complex regulatory network. One single miRNA may have multiple downstream targets participating in different signaling pathways. Conversely, one single gene could be targeted by many miRNAs. Furthermore, miRNAs are also modulated by many genes, for example, regulation of miR-15a and miR-16 by c-myc signaling. This intertwining and reciprocal regulation between miRNAs and genes increases complexity of the regulatory network. Modification of cancer-related miRNAs without tampering with normal cell functions is challenging yet advantageous.

The links between aberrant miRNA expression and etiology of HCC remain unknown. We have described many candidate miRNA targets in HCC and performed regulatory pathway enrichment analysis using KEGG (Kyoto Encyclopedia of Genes and Genomes) [137]. Several cancer-related pathways have been identified; however, some of them have no clear links to tumorigenesis. These data suggest that modification of miRNAs leads to some un- wanted side effects, and raise the question whether all of the deregulated miRNAs are initiating factors for HCC development. It is possible that some of these miRNAs might just be the byproducts of tumorigenesis.

Another barrier to effective clinical treatment using miRNAs is the delivery methods. To date, siRNAs have been used to treat many diseases effectively [138-143]. Many siRNA delivery systems have been developed, including nonselective liposomal delivery, cell-type-specific nanoparticle delivery, and lentiviral delivery. It is possible to use these systems for miRNA delivery because of the similarity between miRNAs and siRNAs. However, introduction of foreign agents, including miRNAs, could activate innate cellular immune responses leading to production of IFNs [144]. High levels of synthetic siRNAs result in saturation of exportin and subsequent inhibition of endogenous pre-miRNA export from the nucleus, which is lethal to cells $[140,145]$. These side effects are prominent in nonselective delivery systems. A cell-type-specific chemical delivery system is still in development, and a few have worked well in in vivo studies. Nevertheless, selective or nonselective chemical delivery systems cannot provide long-term RNAi. Long-term RNAi, which is preferred in chronic liver diseases, requires a viral delivery system. Safety concerns regarding how to target viral vectors to specific cell types with minimal cytotoxicity remain biggest challenge that needs to be circumvented before they can be applied to RNAi-based therapies in humans [146].

The off-target effect could be another drawback limiting the clinical application of miRNA therapies. As a result of the sequence-specific discernment capability of siRNAs and their targets, no sequence-mediated off-target effects have been reported for siRNA-based therapies in clinical trials thus far. However, it might only be a matter of time before this occurs, especially for miRNAs that regulate dozens or even hundreds of targets. The off-target effects of miRNAs on important genes involved in important biological processes may have severe consequences. Matching miRNAs within 3'-UTRs or coding regions of target mRNAs should be carefully evaluated using bioinformatics algorithms. We must be cautious and yet remain optimistic regarding miRNA-related therapeutics. Many questions remain to be clarified before efficient miRNA-based therapies for the treatment of $\mathrm{HCC}$ and other cancers become available.

This work was supported by the National Natural Science Foundation of China (Grant Nos. 30970623 and 31071137), International Science and Technology Cooperation Projects (Grant Nos. $2010 D F A 31840$ and 2010DFB33720), Program for New Century Excellent Talents in University (Grant No. NCET-11-0288), and Beijing Natural Science Foundation (Grant No. 5112030).

1 Berry D A, Herbst R S, Rubin E H. Reports from the 2010 Clinical and Translational Cancer Research Think Tank meeting: design strategies for personalized therapy trials. Clin Cancer Res, 2012, 18: 638--644 
2 Liu L, Miao R, Yang H, et al. Prognostic factors after liver resection for hepatocellular carcinoma: a single-center experience from China. Am J Surg, 2012, 203: 741-750

3 El-Serag H B, Marrero J A, Rudolph L, et al. Diagnosis and treatment of hepatocellular carcinoma. Gastroenterology, 2008,134: 1752-1763

4 Huynh H. Tyrosine kinase inhibitors to treat liver cancer. Expert Opin Emerg Drugs, 2010, 15: 13-26

5 Razumilava N, Gores G J. Sorafenib for HCC: a pragmatic perspective. Oncology (Williston Park), 2011, 25: 300, 302

6 Blum H E. Hepatocellular carcinoma: therapy and prevention. World J Gastroenterol, 2005, 11: 7391-7400

7 Cho Y K. A randomized trial comparing radiofrequency ablation and surgical resection for HCC conforming to the Milan criteria. Ann Surg, 2011, 254: 838-839

8 Chen J W, Kow L, Verran D J, et al. Poorer survival in patients whose explanted hepatocellular carcinoma (HCC) exceeds Milan or UCSF Criteria. An analysis of liver transplantation in HCC in Australia and New Zealand. HPB (Oxford), 2009, 11: 81-89

9 Calin G A, Croce C M. MicroRNA signatures in human cancers. Nat Rev Cancer, 2006, 6: 857-866

10 Lu X, Zhao H, Yang H, et al. A prospective clinical study on early recurrence of hepatocellular carcinoma after hepatectomy. J Surg Oncol, 2009, 100: 488-493

11 Clinkenbeard E L, Butler J E, Spear B T. Pericentral activity of AFP enhancer E3 and glutamine synthetase upstream enhancer in the adult liver are regulated by beta-catenin. Hepatology, 2012

12 Petri A, Lindow M, Kauppinen S. MicroRNA silencing in primates: towards development of novel therapeutics. Cancer Res, 2009, 69: 393-395

13 Mott J L. MicroRNAs involved in tumor suppressor and oncogene pathways: implications for hepatobiliary neoplasia. Hepatology, 2009, 50: 630-637

14 Feng Y, Yu X. Cardinal roles of miRNA in cardiac development and disease. Sci China Life Sci, 2011, 54: 1113-1120

15 Zhang Y, Dong D, Yang B. Atrial remodeling in atrial fibrillation and association between microRNA network and atrial fibrillation. Sci China Life Sci, 2011, 54: 1097-1102

16 Feng W, Feng Y. MicroRNAs in neural cell development and brain diseases. Sci China Life Sci, 2011, 54: 1103-1112

17 Luo J, Teng M, Fan J, et al. Marek's disease virus-encoded microRNAs: genomics, expression and function. Sci China Life Sci, 2010, 53: 1174-1180

18 Zuo J, Wang Y, Liu H, et al. MicroRNAs in tomato plants. Sci China Life Sci, 2011, 54: 599-605

19 He S, Yang Z, Skogerbo G, et al. The properties and functions of virus encoded microRNA, siRNA, and other small noncoding RNAs. Crit Rev Microbiol, 2008, 34: 175-188

20 Visone R, Petrocca F, Croce C M. Micro-RNAs in gastrointestinal and liver disease. Gastroenterology, 2008, 135: 1866-1869

21 Montalto G, Cervello M, Giannitrapani L, et al. Epidemiology, risk factors, and natural history of hepatocellular carcinoma. Ann N Y Acad Sci, 2002, 963: 13-20

22 Yang C, Wei W. The miRNA expression profile of the uveal melanoma. Sci China Life Sci, 2011, 54: 351-358

23 Wu J, Wang C, Du Z, et al. Identification of Pns12 as the second silencing suppressor of Rice gall dwarf virus. Sci China Life Sci, 2011, 54: 201-208

24 Wang X, Zhao H, Xu Q, et al. HPtaa database-potential target genes for clinical diagnosis and immunotherapy of human carcinoma. Nucleic Acids Res, 2006, 34: D607-612

25 Zhang X, Zhang H, Ye L. Effects of hepatitis B virus X protein on the development of liver cancer. J Lab Clin Med, 2006, 147: 58-66

26 Wang Y, Cui F, Lv Y, et al. HBsAg and HBx knocked into the p21 locus causes hepatocellular carcinoma in mice. Hepatology, 2004, 39: $318-324$

27 Lara-Pezzi E, Majano P L, Yanez-Mo M, et al. Effect of the hepatitis $\mathrm{B}$ virus $\mathrm{HBx}$ protein on integrin-mediated adhesion to and migration on extracellular matrix. J Hepatol, 2001, 34: 409-415
28 Xia L M, Huang W J, Wu J G, et al. HBx protein induces expression of MIG and increases migration of leukocytes through activation of NF-kappaB. Virology, 2009, 385: 335-342

29 Chung T W, Lee Y C, Kim C H. Hepatitis B viral HBx induces matrix metalloproteinase-9 gene expression through activation of ERK and PI-3K/AKT pathways: involvement of invasive potential. FASEB J, 2004, 18: 1123-1125

30 Zhang F, Wang Q, Ye L, et al. Hepatitis B virus X protein upregulates expression of calpain small subunit 1 via nuclear factor-kappaB/p65 in hepatoma cells. J Med Virol, 2010, 82: 920-928

31 Zhang $\mathrm{X}$, Liu $\mathrm{S}$, Hu $\mathrm{T}$, et al. Up-regulated microRNA-143 transcribed by nuclear factor kappa B enhances hepatocarcinoma metastasis by repressing fibronectin expression. Hepatology, 2009, 50: 490-499

32 Yin Y, Zhao Y, Wang J, et al. antiCODE: a natural sense-antisense transcripts database. BMC Bioinformatics, 2007, 8: 319

33 Gao W, Yu Y, Cao H, et al. Deregulated expression of miR-21, miR-143 and miR-181a in non small cell lung cancer is related to clinicopathologic characteristics or patient prognosis. Biomed Pharmacother, 2010, 64: 399-408

34 Kitade Y, Akao Y. MicroRNAs and their therapeutic potential for human diseases: microRNAs, miR-143 and -145 , function as anti-oncomirs and the application of chemically modified miR-143 as an anti-cancer drug. J Pharmacol Sci, 2010, 114: 276-280

35 Dasari V R, Kaur K, Velpula K K, et al. Upregulation of PTEN in glioma cells by cord blood mesenchymal stem cells inhibits migration via downregulation of the PI3K/Akt pathway. PLoS ONE, 2010, 5: e10350

36 Du B, Ma L M, Huang M B, et al. High glucose down-regulates miR-29a to increase collagen IV production in HK-2 cells. FEBS Lett, 2010, 584: 811-816

37 Narbus C M, Israelow B, Sourisseau M, et al. HepG2 cells expressing microRNA miR-122 support the entire hepatitis $\mathrm{C}$ virus life cycle. J Virol, 2011, 85: 12087-12092

38 Cui Y, Su W Y, Xing J, et al. MiR-29a inhibits cell proliferation and induces cell cycle arrest through the downregulation of p42.3 in human gastric cancer. PLoS ONE, 2011, 6: e25872

39 Dudek H, Datta S R, Franke T F, et al. Regulation of neuronal survival by the serine-threonine protein kinase Akt. Science, 1997, 275: 661-665

40 Meng F, Henson R, Wehbe-Janek H, et al. MicroRNA-21 regulates expression of the PTEN tumor suppressor gene in human hepatocellular cancer. Gastroenterology, 2007, 133: 647-658

41 Garofalo M, Di Leva G, Romano G, et al. miR-221\&222 regulate TRAIL resistance and enhance tumorigenicity through PTEN and TIMP3 downregulation. Cancer Cell, 2009, 16: 498-509

42 Kong G, Zhang J, Zhang S, et al. Upregulated microRNA-29a by hepatitis $\mathrm{B}$ virus $\mathrm{X}$ protein enhances hepatoma cell migration by targeting PTEN in cell culture model. PLoS ONE, 2011, 6: e19518

43 Korenaga M, Wang T, Li Y, et al. Hepatitis C virus core protein inhibits mitochondrial electron transport and increases reactive oxygen species (ROS) production. J Biol Chem, 2005, 280: 3748137488

44 Irshad M, Dhar I. Hepatitis C virus core protein: an update on its molecular biology, cellular functions and clinical implications. Med Princ Pract, 2006, 15: 405-416

45 Pedersen I M, Cheng G, Wieland S, et al. Interferon modulation of cellular microRNAs as an antiviral mechanism. Nature, 2007, 449: 919-922

46 Hou W, Tian Q, Zheng J, et al. MicroRNA-196 represses Bach1 protein and hepatitis $\mathrm{C}$ virus gene expression in human hepatoma cells expressing hepatitis C viral proteins. Hepatology, 2010, 51: 1494-1504

47 Shan Y, Lambrecht R W, Ghaziani T, et al. Role of Bach-1 in regulation of heme oxygenase-1 in human liver cells: insights from studies with small interfering RNAS. J Biol Chem, 2004, 279: 51769-51774

48 Hornstein E, Mansfield J H, Yekta S, et al. The microRNA miR-196 acts upstream of Hoxb8 and Shh in limb development. Nature, 2005, 
438: $671-674$

49 Kitamuro $\mathrm{T}$, Takahashi $\mathrm{K}$, Ogawa $\mathrm{K}$, et al. Bach1 functions as a hypoxia-inducible repressor for the heme oxygenase-1 gene in human cells. J Biol Chem, 2003, 278: 9125-9133

50 Shan Y, Zheng J, Lambrecht $\mathrm{R} \mathrm{W}$, et al. Reciprocal effects of micro-RNA-122 on expression of heme oxygenase-1 and hepatitis $\mathrm{C}$ virus genes in human hepatocytes. Gastroenterology, 2007, 133: 1166-1174

51 Zhu Z, Wilson A T, Mathahs M M, et al. Heme oxygenase-1 suppresses hepatitis $\mathrm{C}$ virus replication and increases resistance of hepatocytes to oxidant injury. Hepatology, 2008, 48: 1430-1439

52 Elbirt K K, Bonkovsky H L. Heme oxygenase: recent advances in understanding its regulation and role. Proc Assoc Am Physicians, 1999, 111: 438-447

53 Lohmann V, Korner F, Koch J, et al. Replication of subgenomic hepatitis C virus RNAs in a hepatoma cell line. Science, 1999, 285: $110-113$

54 Chang J, Nicolas E, Marks D, et al. miR-122, a mammalian liver-specific microRNA, is processed from hor mRNA and may downregulate the high affinity cationic amino acid transporter CAT-1. RNA Biol, 2004, 1: 106-113

55 Lanford R E, Hildebrandt-Eriksen E S, Petri A, et al. Therapeutic silencing of microRNA-122 in primates with chronic hepatitis C virus infection. Science, 2010, 327: 198-201

56 Wang G, Dong X, Hu J, et al. Long-term ex vivo monitoring of in vivo microRNA activity in liver using a secreted luciferase sensor. Sci China Life Sci, 2011, 54: 418-425

57 Jopling C L, Norman K L, Sarnow P. Positive and negative modulation of viral and cellular mRNAs by liver-specific microRNA miR-122. Cold Spring Harb Symp Quant Biol, 2006, 71: 369-376

58 Young D D, Connelly C M, Grohmann C, et al. Small molecule modifiers of microRNA miR-122 function for the treatment of hepatitis $\mathrm{C}$ virus infection and hepatocellular carcinoma. J Am Chem Soc, 2010, 132: 7976-7981

59 Moradpour D, Penin F, Rice C M. Replication of hepatitis C virus. Nat Rev Microbiol, 2007, 5: 453-463

60 Song Y, Friebe P, Tzima E, et al. The hepatitis C virus RNA 3'untranslated region strongly enhances translation directed by the internal ribosome entry site. J Virol, 2006, 80: 11579-11588

61 Bradrick S S, Walters R W, Gromeier M. The hepatitis C virus $3^{\prime}$-untranslated region or a poly(A) tract promote efficient translation subsequent to the initiation phase. Nucleic Acids Res, 2006, 34: 1293-1303

62 Isken $\mathrm{O}$, Baroth $\mathrm{M}$, Grassmann $\mathrm{C}$ W, et al. Nuclear factors are involved in hepatitis C virus RNA replication. RNA, 2007, 13: $1675-1692$

63 Niepmann M. Activation of hepatitis C virus translation by a liver-specific microRNA. Cell Cycle, 2009, 8: 1473-1477

64 Norman K L, Sarnow P. Modulation of hepatitis C virus RNA abundance and the isoprenoid biosynthesis pathway by microRNA miR-122 involves distinct mechanisms. J Virol, 2010, 84: 666-670

65 Jopling C L, Yi M, Lancaster A M, et al. Modulation of hepatitis C virus RNA abundance by a liver-specific MicroRNA. Science, 2005, 309: 1577-1581

66 Appel N, Bartenschlager R. A novel function for a micro RNA: negative regulators can do positive for the hepatitis $\mathrm{C}$ virus. Hepatology, 2006, 43: 612-615

67 Banaudha K, Kaliszewski M, Korolnek T, et al. MicroRNA silencing of tumor suppressor DLC-1 promotes efficient hepatitis C virus replication in primary human hepatocytes. Hepatology, 2011, 53: 53- 61

68 Nakada C, Matsuura K, Tsukamoto Y, et al. Genome-wide microRNA expression profiling in renal cell carcinoma: significant downregulation of miR-141 and miR-200c. J Pathol, 2008, 216: 418-427

69 Liu X, Wang T, Wakita T, et al. Systematic identification of microRNA and messenger RNA profiles in hepatitis $\mathrm{C}$ virus-infected human hepatoma cells. Virology, 2010, 398: 57-67

70 Yang Z, Ren F, Liu C, et al. dbDEMC: a database of differentially expressed miRNAs in human cancers. BMC Genomics, 2010, 11: S5
$71 \mathrm{Li} H \mathrm{P}$, Leu $\mathrm{Y} \mathrm{W}$, Chang $\mathrm{Y}$ S. Epigenetic changes in virus-associated human cancers. Cell Res, 2005, 15: 262-271

72 Huang J, Wang Y, Guo Y, et al. Down-regulated microRNA-152 induces aberrant DNA methylation in hepatitis B virus-related hepatocellular carcinoma by targeting DNA methyltransferase 1 . Hepatology, 2010, 52: 60-70

73 Datta J, Kutay H, Nasser M W, et al. Methylation mediated silencing of microRNA-1 gene and its role in hepatocellular carcinogenesis. Cancer Res, 2008, 68: 5049-5058

74 Law P T, Wong N. Emerging roles of microRNA in the intracellular signaling networks of hepatocellular carcinoma. J Gastroenterol Hepatol, 2011, 26: 437-449

75 Shimizu S, Takehara $\mathrm{T}$, Hikita $\mathrm{H}$, et al. The let-7 family of microRNAs inhibits Bcl-xL expression and potentiates sorafenibinduced apoptosis in human hepatocellular carcinoma. J Hepatol, 2010, 52: 698-704

76 Tsang W P, Kwok T T. Epigallocatechin gallate up-regulation of miR-16 and induction of apoptosis in human cancer cells. J Nutr Biochem, 2010, 21: 140-146

77 Tsuruta T, Kozaki K, Uesugi A, et al. miR-152 is a tumor suppressor microRNA that is silenced by DNA hypermethylation in endometrial cancer. Cancer Res, 2011, 71: 6450-6462

78 Tsang T Y, Tang W Y, Chan J Y, et al. P-glycoprotein enhances radiation-induced apoptotic cell death through the regulation of miR-16 and Bcl-2 expressions in hepatocellular carcinoma cells. Apoptosis, 2011, 16: 524-535

79 Sang $\mathrm{X}$, Zhao $\mathrm{H}$, Lu X, et al. Prediction and identification of tumor-specific noncoding RNAs from human UniGene. Med Oncol, 2010, 27: 894-898

80 Chen W S, Leung C M, Pan H W, et al. Silencing of miR-1-1 and miR-133a-2 cluster expression by DNA hypermethylation in colorectal cancer. Oncol Rep, 2012, 28: 1069-1076

81 Chung $\mathrm{G}$ E, Yoon $\mathrm{J} \mathrm{H}$, Myung S J, et al. High expression of microRNA-15b predicts a low risk of tumor recurrence following curative resection of hepatocellular carcinoma. Oncol Rep, 2010, 23: 113-119

82 Zhang Y. Progress, challenges and new concepts in microRNAs. Sci China Life Sci, 2011, 54: 1096

83 Pineau P, Volinia S, McJunkin K, et al. miR-221 overexpression contributes to liver tumorigenesis. Proc Natl Acad Sci USA, 2010, 107: 264-269

84 Xu C, Liu S, Fu H, et al. MicroRNA-193b regulates proliferation, migration and invasion in human hepatocellular carcinoma cells. Eur J Cancer, 2010, 46: 2828-2836

85 Furuta M, Kozaki K I, Tanaka S, et al. miR-124 and miR-203 are epigenetically silenced tumor-suppressive microRNAs in hepatocellular carcinoma. Carcinogenesis, 2010, 31: 766-776

86 Zhao W Y, Wang D D, Song M Q, et al. Role of microRNA-223 and its target gene oncogene c-myc in hepatocellular carcinoma pathogenesis (in Chinese). Zhonghua Gan Zang Bing Za Zhi, 2011, 19: 114-117

87 Cheng J, Zhou L, Xie Q F, et al. The impact of miR-34a on protein output in hepatocellular carcinoma HepG2 cells. Proteomics, 2010, 10: $1557-1572$

$88 \mathrm{Hu}$ L, Ibrahim S, Liu C, et al. Thrombin induces tumor cell cycle activation and spontaneous growth by down-regulation of $\mathrm{p} 27 \mathrm{Kip} 1$, in association with the up-regulation of Skp2 and MiR-222. Cancer Res, 2009, 69: 3374-3381

89 Fornari F, Milazzo M, Chieco P, et al. MiR-199a-3p regulates mTOR and c-Met to influence the doxorubicin sensitivity of human hepatocarcinoma cells. Cancer Res, 2010, 70: 5184-5193

90 Henry J C, Park J K, Jiang J, et al. miR-199a-3p targets CD44 and reduces proliferation of CD44 positive hepatocellular carcinoma cell lines. Biochem Biophys Res Commun, 2010, 403: 120-125

91 Orian-Rousseau V, Chen L, Sleeman J P, et al. CD44 is required for two consecutive steps in HGF/c-Met signaling. Genes Dev, 2002, 16 3074-3086

92 Mitchell P S, Parkin R K, Kroh E M, et al. Circulating microRNAs as stable blood-based markers for cancer detection. Proc Natl Acad 
Sci USA, 2008, 105: 10513-10518

93 Chen X, Ba Y, Ma L, et al. Characterization of microRNAs in serum: a novel class of biomarkers for diagnosis of cancer and other diseases. Cell Res, 2008, 18: 997-1006

94 Gilad S, Meiri E, Yogev Y, et al. Serum microRNAs are promising novel biomarkers. PLoS ONE, 2008, 3: e3148

95 Wang Q Z, Xu W, Habib N, et al. Potential uses of microRNA in lung cancer diagnosis, prognosis, and therapy. Curr Cancer Drug Targets, 2009, 9: 572-594

96 Sukata T, Sumida K, Kushida M, et al. Circulating microRNAs, possible indicators of progress of rat hepatocarcinogenesis from early stages. Toxicol Lett, 2011, 200: 46-52

97 Zhou J, Yu L, Gao X, et al. Plasma microRNA panel to diagnose hepatitis B virus-related hepatocellular carcinoma. J Clin Oncol, 2011, 29: 4781-4788

98 Gui J, Tian Y, Wen X, et al. Serum microRNA characterization identifies miR-885-5p as a potential marker for detecting liver pathologies. Clin Sci (Lond), 2011, 120: 183-193

99 Li L M, Hu Z B, Zhou Z X, et al. Serum microRNA profiles serve as novel biomarkers for HBV infection and diagnosis of HBV-positive hepatocarcinoma. Cancer Res, 2010, 70: 9798-9807

100 Qu K Z, Zhang K, Li H, et al. Circulating microRNAs as biomarkers for hepatocellular carcinoma. J Clin Gastroenterol, 2011, 45: 355360

101 Li J, Wang Y, Yu W, et al. Expression of serum miR-221 in human hepatocellular carcinoma and its prognostic significance. Biochem Biophys Res Commun, 2011, 406: 70-73

102 Miao R Y, Zhao H T, Yang H Y, et al. Postoperative adjuvant antiviral therapy for hepatitis $\mathrm{B} / \mathrm{C}$ virus-related hepatocellular carcinoma: a meta-analysis. World J Gastroenterol, 2010, 16: 29312942

$103 \mathrm{Xu} \mathrm{J}$, Wu C, Che X, et al. Circulating microRNAs, miR-21, miR-122, and miR-223, in patients with hepatocellular carcinoma or chronic hepatitis. Mol Carcinog, 2011, 50: 136-142

104 Pavlidis N, Briasoulis E, Hainsworth J, et al. Diagnostic and therapeutic management of cancer of an unknown primary. Eur $\mathbf{J}$ Cancer, 2003, 39: 1990-2005

105 Landgraf P, Rusu M, Sheridan R, et al. A mammalian microRNA expression atlas based on small RNA library sequencing. Cell, 2007, 129: $1401-1414$

106 Barshack I, Meiri E, Rosenwald S, et al. Differential diagnosis of hepatocellular carcinoma from metastatic tumors in the liver using microRNA expression. Int $\mathrm{J}$ Biochem Cell Biol, 2010, 42: 1355-1362

107 Wong C C, Wong C M, Tung E K, et al. The microRNA miR-139 suppresses metastasis and progression of hepatocellular carcinoma by down-regulating Rho-kinase 2. Gastroenterology, 2011, 140: 322- 331

108 Sato F, Hatano E, Kitamura K, et al. MicroRNA profile predicts recurrence after resection in patients with hepatocellular carcinoma within the Milan Criteria. PLoS ONE, 2011, 6: e16435

109 Wong Q W, Ching A K, Chan A W, et al. MiR-222 overexpression confers cell migratory advantages in hepatocellular carcinoma through enhancing AKT signaling. Clin Cancer Res, 2010, 16: 867875

110 Ji J, Zhao L, Budhu A, et al. Let-7g targets collagen type I alpha2 and inhibits cell migration in hepatocellular carcinoma. J Hepatol, 2010, 52: 690-697

111 Budhu A, Jia H L, Forgues M, et al. Identification of metastasisrelated microRNAs in hepatocellular carcinoma. Hepatology, 2008, 47: 897-907

112 Cheng A L, Kang Y K, Chen Z, et al. Efficacy and safety of sorafenib in patients in the Asia-Pacific region with advanced hepatocellular carcinoma: a phase III randomised, double-blind, placebo-controlled trial. Lancet Oncol, 2009, 10: 25-34

113 Liu L, Cao Y, Chen C, et al. Sorafenib blocks the RAF/MEK/ERK pathway, inhibits tumor angiogenesis, and induces tumor cell apoptosis in hepatocellular carcinoma model PLC/PRF/5. Cancer Res, 2006, 66: 11851-11858
114 Cominetti M R, Martin A C, Ribeiro J U, et al. Inhibition of platelets and tumor cell adhesion by the disintegrin domain of human ADAM9 to collagen I under dynamic flow conditions. Biochimie, 2009, 91: 1045-1052

115 Josson S, Anderson C S, Sung S Y, et al. Inhibition of ADAM9 expression induces epithelial phenotypic alterations and sensitizes human prostate cancer cells to radiation and chemotherapy. Prostate, 2011, 71: 232-240

116 Peduto L. ADAM9 as a potential target molecule in cancer. Curr Pharm Des, 2009, 15: 2282-2287

117 Xu Q, Liu X, Cai Y, et al. RNAi-mediated ADAM9 gene silencing inhibits metastasis of adenoid cystic carcinoma cells. Tumour Biol, 2010, 31: 217-224

118 Zhou C, Liu J, Li Y, e al. microRNA-1274a, a modulator of sorafenib induced a disintegrin and metalloproteinase 9 (ADAM9) down-regulation in hepatocellular carcinoma. FEBS Lett, 2011, 585: $1828-1834$

119 Bai S, Nasser M W, Wang B, et al. MicroRNA-122 inhibits tumorigenic properties of hepatocellular carcinoma cells and sensitizes these cells to sorafenib. J Biol Chem, 2009, 284: 32015-32027

120 Ji J, Shi J, Budhu A, et al. MicroRNA expression, survival, and response to interferon in liver cancer. N Engl J Med, 2009, 361: $1437-1447$

121 Calin G A, Dumitru C D, Shimizu M, et al. Frequent deletions and down-regulation of microRNA genes miR15 and miR16 at 13q14 in chronic lymphocytic leukemia. Proc Natl Acad Sci USA, 2002, 99: 15524-15529

122 He L, Thomson J M, Hemann M T, et al. A microRNA polycistron as a potential human oncogene. Nature, 2005, 435: 828-833

123 O'Donnell K A, Wentzel E A, Zeller K I, et al. c-Myc-regulated microRNAs modulate E2F1 expression. Nature, 2005, 435: 839-843

124 Kutay H, Bai S, Datta J, et al. Downregulation of miR-122 in the rodent and human hepatocellular carcinomas. J Cell Biochem, 2006, 99: 671-678

125 Jiang Q, Wang Y, Hao Y, et al. miR2Disease: a manually curated database for microRNA deregulation in human disease. Nucleic Acids Res, 2009, 37: D98-104

126 Sarver A L, Phalak R, Thayanithy V, et al. S-MED: sarcoma microRNA expression database. Lab Invest, 2010, 90: 753-761

127 Calin G A, Sevignani C, Dumitru C D, et al. Human microRNA genes are frequently located at fragile sites and genomic regions involved in cancers. Proc Natl Acad Sci USA, 2004, 101: 2999-3004

128 Chen H, Chen Q, Fang M, et al. microRNA-181b targets MLK2 in HL-60 cells. Sci China Life Sci, 2010, 53: 101-106

129 Lu J, Getz G, Miska E A, et al. MicroRNA expression profiles classify human cancers. Nature, 2005, 435: 834-838

130 Kanehisa M, Araki M, Goto S, et al. KEGG for linking genomes to life and the environment. Nucleic Acids Res, 2008, 36: D480-484

131 Xiangji L, Feng X, Qingbao C, et al. Knockdown of HBV surface antigen gene expression by a lentiviral microRNA-based system inhibits HBV replication and HCC growth. J Viral Hepat, 2011, 18: $653-660$

132 Jin W B, Wu F L, Kong D, et al. HBV-encoded microRNA candidate and its target. Comput Biol Chem, 2007, 31: 124-126

133 Ely A, Naidoo T, Mufamadi S, et al. Expressed anti-HBV primary microRNA shuttles inhibit viral replication efficiently in vitro and in vivo. Mol Ther, 2008, 16: 1105-1112

134 Chen G, Wang C, Shi T. Overview of available methods for diverse RNA-Seq data analyses. Sci China Life Sci, 2011, 54: 1121-1128

135 Qiu L, Fan H, Jin W, et al. miR-122-induced down-regulation of HO-1 negatively affects miR-122-mediated suppression of HBV. Biochem Biophys Res Commun, 2010, 398: 771-777

136 Li S, Yu B, Wang Y, et al. Identification and functional annotation of novel microRNAs in the proximal sciatic nerve after sciatic nerve transection. Sci China Life Sci, 2011, 54: 806-812

137 Hao M, Zheng S, Ding H, et al. Regulation of microRNA-122 on $\mathrm{HBV}$ replication by targeting HBx sequence (in Chinese). Sheng Wu Yi Xue Gong Cheng Xue Za Zhi, 2011, 28: 784-789, 803 
138 Su C, Hou Z, Zhang C, et al. Ectopic expression of microRNA-155 enhances innate antiviral immunity against HBV infection in human hepatoma cells. Virol J, 2011, 8: 354

139 de Veer M J, Sledz C A, Williams B R. Detection of foreign RNA: implications for RNAi. Immunol Cell Biol, 2005, 83: 224-228

140 Grimm D, Streetz K L, Jopling C L, et al. Fatality in mice due to oversaturation of cellular microRNA/short hairpin RNA pathways. Nature, 2006, 441: 537-541

141 Kim D H, Rossi J J. Strategies for silencing human disease using RNA interference. Nat Rev Genet, 2007, 8: 173-184

142 Shah Y M, Morimura K, Yang Q, et al. Peroxisome proliferatoractivated receptor alpha regulates a microRNA-mediated signaling cascade responsible for hepatocellular proliferation. Mol Cell Biol, 2007, 27: 4238-4247
143 Lan F F, Wang H, Chen Y C, et al. Hsa-let-7g inhibits proliferation of hepatocellular carcinoma cells by downregulation of c-Myc and upregulation of p16(INK4A). Int J Cancer, 2011, 128: 319-331

144 Skawran B, Steinemann D, Becker T, et al. Loss of $13 \mathrm{q}$ is associated with genes involved in cell cycle and proliferation in dedifferentiated hepatocellular carcinoma. Mod Pathol, 2008, 21: 1479-1489

$145 \mathrm{Wu}$ G, Yu F, Xiao Z, et al. Hepatitis B virus $\mathrm{X}$ protein downregulates expression of the miR-16 family in malignant hepatocytes in vitro. Br J Cancer, 2011, 105: 146-153

146 Connolly E, Melegari M, Landgraf P, et al. Elevated expression of the miR-17-92 polycistron and miR-21 in hepadnavirus-associated hepatocellular carcinoma contributes to the malignant phenotype. Am J Pathol, 2008, 173: 856-864

Open Access This article is distributed under the terms of the Creative Commons Attribution License which permits any use, distribution, and reproduction in any medium, provided the original author(s) and source are credited. 